\title{
EDUCAÇÃO, ACESSO À INFORMAÇÃO E PARTICIPAÇÃO POPULAR: UMA ANÁLISE DAS MEDIDAS DO ESTADO DO PARÁ ACERCA DA TENTATIVA DE ADOÇÃO DE ESCOLAS CHARTER
}

\section{EDUCATION, ACESS TO INFORMATION AND POPULAR PARTICIPATION: AN ANALYSIS ON THE MEASURES OF THE PARÁ STATE ABOUT THE ATTEMPT OF ADOPT THE CHARTER SCHOOLS MODEL}

\author{
${ }^{1}$ Bianca Araujo de Oliveira Pereira
}

\section{RESUMO}

Este artigo visa debater acerca da participação popular nas medidas do Estado do Pará, o qual tentou utilizar o modelo de escola charter para melhorias da educação pública. Para isso, é feita uma breve explanação acerca da participação popular e sua relação com o direito à informação. Em seguida, é explicado no que consiste uma escola charter e as diferentes formas de uso do aparato privado. Abordamos as notícias sobre as medidas do Governo estadual e a falta de informações claras e acessíveis nos veículos oficiais. Por fim, apresentam-se as conclusões.

Palavras-chave: Educação. Participação popular. Acesso à informação. Políticas Públicas. Escolas Charter.

\begin{abstract}
This article aims to discuss the popular participation within the State of Pará measures, which tried to use school model charter for improvement of public education. For this, it is made a brief explanation about popular participation and its relation to the right to information. Then, it is explained what is a charter school and the different forms of use of private apparatus by the State. We approach the news about the governement's measures and the lack of clear and accessible information on official vehicles. Finally, we present the conclusions.
\end{abstract}

Keywords: Education. Popular participation. Acess to information. Public policy. Charter Schools.

\footnotetext{
${ }^{1}$ Discente do Programa de Pós-Graduação em Direito pela Universidade Federal do Pará, Belém, Pará, (Brasil). Bolsista CAPES. Membro da Clínica de Direitos Humanos do Centro Universitário do Estado do Pará. E-mail: bianca_araujo19@hotmail.com
} 


\section{INTRODUÇÃO}

Com o fim da ditadura militar e a promulgação da Constituição Federal de 1988, a participação popular se apresenta como uma conquista em prol da democracia e dos direitos humanos, ao viabilizar o diálogo entre sociedade civil e Estado como uma prática de participação política e de fiscalização dos atos estatais. Entretanto, este instrumento muitas vezes é preterido, em função de uma atuação estatal que opera a partir da lógica de "portas fechadas", sem promover o diálogo, o acesso a informações suficientes e a imposição de medidas que não condizem com as reais ânsias e necessidades da sociedade como um todo. Desta forma, são feridos os direitos humanos de participação política e à informação conjuntamente, se o Estado age neste sentido.

Partindo desse pressuposto, o presente artigo busca investigar (sem, entretanto, esgotar a temática) as medidas do Estado do Pará que foram veiculadas no ano de 2015, e que buscavam a melhoria do ensino básico público, através da realização de parcerias público- privadas e financiamento de organismos internacionais, para a adoção do chamado modelo de escola charter.

Nesse ínterim, a investigação se debruça sobre os temas da participação popular e da transparência no acesso a informações que digam respeito à atuação estatal neste caso específico. Desta forma, diante do cenário exposto, pergunta-se: as medidas sinalizadas pelo Governo do Estado do Pará quanto a adoção de escolas charter foram acompanhadas de participação dos setores interessados e de transparência e acesso à informação? Objetiva-se, portanto, discutir acerca da natureza deste modelo de escola e das medidas estatais, levando em conta que os direitos de participação e à informação são direitos humanos tutelados pela Constituição Federal de 1988.

Para realizar tal discussão, o presente artigo recorre a pesquisas bibliográficas de autores que tratam da questão da participação popular, além de compreender a diferenciação entre privatização, terceirização, uso de Organizações Sociais e Parcerias Público-Privadas. Em um segundo momento, buscam-se informações fora do ambiente acadêmico, através de reportagens e tentativas de contato com órgãos do Estado, para concluir se, de fato, houve alguma forma de participação e acesso à informação no caso em estudo.

\section{COMPREENDENDO A PARTICIPAÇÃO POPULAR: UMA BREVE INTRODUÇÃO}


A participação popular pode ser entendida como a participação das classes populares nos processos de tomada de decisão (VALLA, 1998, p. 8). Essa participação se dá dentro de uma elaboração de políticas públicas, realizada pelo Estado; especificamente na América Latina, que historicamente passou por períodos ditatoriais e de justiça de transição, a participação popular pode ser entendida não só como avanço democrático, mas também forma de participação política, pois possibilita que os indivíduos se manifestem acerca das decisões que influenciam suas vidas e seus interesses.

Além disso, a participação popular é um sinalizador para a relação entre indivíduos e Estado, e de como este encara os recursos públicos, pois são estes recursos que serão redistribuídos e que subsidiarão a execução de políticas públicas que efetivarão os direitos humanos em âmbito interno (VALLA, 2000, p. 252).

Segundo Valla (2000, p. 253), para melhor compreendermos a participação popular, é interessante entender, primeiramente, a participação social. Esta compreende "as múltiplas ações que diferentes forças sociais desenvolvem para influenciar a formulação, execução, fiscalização e avaliação das políticas públicas e/ou serviços básicos na área social”. Logo, a participação popular é uma espécie de participação social, com um enfoque especial nas classes menos favorecidas da sociedade.

Entretanto, é preciso atentar que a participação popular não deve ser vista de forma pejorativa, como se os indivíduos que dependem diretamente das prestações estatais para alcançar seus projetos de vida fossem uma massa sem informação, e que deve ser protegida a todo custo de si mesma, através de atitudes paternalistas do Estado.

Na verdade, a participação popular deve ser entendida no sentido de empoderar essas pessoas, possibilitando a sua presença nos processos de tomada de decisões e controle do Estado, como agentes. Hoje, em função das mídias sociais e do expressivo uso da internet por jovens e adultos, é possível dizer que há um interesse maior nas questões que envolvem as prestações públicas, e isso é demonstração de que as pessoas, independentemente de sua classe social, querem participar como atores nas tomadas de decisões concernentes a assuntos públicos.

Segundo Abramovich (2006, p. 45), a participação, enquanto princípio, é um ponto crucial nas estratégias e políticas para o desenvolvimento, como uma forma de identificar suas necessidades e prioridades a nível local ou comunitário, estando intimamente relacionada com o exercício de direitos como a liberdade de expressão e de participação política. É primordial, portanto, analisar em que medida os setores que são beneficiários das políticas públicas estão 
tendo dificuldade em exercer esses direitos, já que isso poderá influenciar o sucesso das políticas públicas.

No Brasil, a Constituição Federal de 1988 possibilitou ao cidadão a participação no cenário político, não somente através do voto, mas também na fiscalização e discussão de políticas públicas. Entretanto, em função de como o Estado se porta perante o cidadão, esta participação muitas vezes acaba por não ser exercida.

Desde a repressão violenta a protestos populares, ferindo o direito de liberdade de expressão e de livre associação, até o uso de instrumentos inapropriados para a formulação de políticas públicas (vide a nova "reforma" educacional efetuada pelo Governo Federal, através da Medida Provisória $n^{\circ} 746 / 2016$ ), que ferem o princípio da legalidade estrita, aplicável à administração pública, o direito de participação popular é mitigado, e as propostas não são discutidas pela sociedade civil em diálogo com o Estado.

Dito isso, é evidente que a democracia é mais do que um sistema de eleições institucionalizado. É também expressa no direito de associação, na liberdade sindical, na liberdade de expressão, e no direito à informação, sendo que este último se concretiza através do adequado acesso a informações públicas que tenham conteúdo suficiente que possibilitem a avaliação e físcalização das políticas e decisões que afetem as pessoas diretamente (ABRAMOVICH, 2006, p. 46).

Em outro sentido, o Estado do Pará, no ano de 2015, anunciou que iria realizar o repasse de cerca de 50 escolas públicas a parceiros privados, para que fosse instituído o modelo de escola charter no Estado. Mas essa medida utilizou a participação popular e garantiu o direito de acesso à informação? E, caso tenha utilizado, como se deu essa participação e quais foram as dificuldades no caminho?

\section{ASPECTOS IMPORTANTES ACERCA DAS NOÇÕES DE ESCOLA CHARTER}

Antes de adentrar na avaliação propriamente dita acerca do processo de participação popular no caso em análise, é preciso explicar o que é, exatamente uma escola charter. Escolas charter (ou, no inglês, Charter School), um modelo muito difundido nos EUA, são entendidas como escolas fundadas pelo setor público que posteriormente ganham autonomia do Estado e ficam livres das regulações estatais, em troca de bons resultados (TOMA e ZIMMER, 2011, p. 2). 
Segundo defensores norte-americanos deste modelo, há maior liberdade na escolha dos pais quanto às escolas e a competição destas por alunos aumenta a qualidade do ensino. Os defensores também afirmam que as Charter Schools poderiam criar um fornecimento mais inovador, eficiente e efetivo da educação (TOMA e ZIMMER, 2011, pag. 2). Opositores, entretanto, afirmam que o dinheiro investido nessas escolas irá desviar os recursos das instituições de ensino públicas, e isso por consequência irá piorar o desempenho desses alunos. Segundo Toma e Zimmer (2011, pag. 2), apesar de vasta literatura existente sobre o tema, não há consenso sobre se as Charter Schools melhoram a educação e o rendimento dos alunos.

Entretanto, estudos buscam desvendar esta questão, principalmente sobre o motivo das divergências acerca dos resultados obtidos pelo modelo (ZIMMER, GILL, BOOKER, LAVERTU E WITTE, 2012 e DAVID E RAYMOND, 2012). Alguns estudos procuram investigar o porquê de algumas escolas obterem bom desempenho, enquanto outras obtêm desempenho igual ou pior que o de escolas públicas tradicionais (CARRUTHERS, 2012, CARLSON, LAVERY E WITTE, 2012 E STUIT E SMITH, 2012).

Em estudo, Carlson, Lavery e Witte (2012) investigam a fiscalização nas Charter Schools, examinando a relação entre tipos de Charter Schools autorizadas a atuarem nos Estados Unidos e os resultados nos testes de pontuação, utilizando dados do estado norteamericano de Minnesota. Stuit e Smith (2012), por sua vez, focam na figura do professor, através de dados das escolas, para investigar os padrões de contratação dos educadores. A análise sugere que o desgaste desses profissionais durante a vigência do contrato é maior nessas escolas do que nas públicas porque, em parte, os professores das Charter Schools são mais novos e inexperientes. Mas a falta de sindicalização também é apontada como causa de muitos contratos feitos e desfeitos nesses ambientes.

Winters (2012) examina dados da cidade de Nova York em um período de quatro anos, e utiliza a percentagem de alunos que deixam as escolas públicas tradicionais para ingressarem nas escolas charter em determinado ano, enquanto mede o grau esperado de competição sobre aquela escola. Os resultados indicam um efeito pequeno, mas positivo na proficiência acadêmica dos alunos que continuaram nas escolas públicas.

A competição também afeta os custos da educação. Gronberg, Jansen e Taylor (2012) utilizam dados do estado do Texas em um período de quatro anos, para examinar se as Charter Schools são mais baratas que as escolas públicas e examinam o tipo de eficiência absoluta de cada espécie de escola. Preston, Goldring, Berends e Cannata (2012) investigam a questão da inovação nas escolas charter, se de fato elas são um ambiente mais criativo e se isso atrai os 
estudantes. Para isso, utilizam dados de vários aspectos das Charter Schools como contratação de equipe e políticas de apoio aos alunos.

Levin (2012) traz questões provocativas para o futuro das Charter Schools, através de uma indagação: e se todo um distrito de uma cidade norte-americana adotasse as Chartes Schools? (e isso pode ser traduzido para a realidade brasileira como "e se toda uma cidade adotasse Charter Schools?"). Quais implicações morais, econômicas e de resultados poderiam ser esperadas? Levin força a reflexão das escolhas e responsabilidades de uma sociedade democrática em educar as futuras gerações de crianças e adolescentes.

Além disso, é interessante citar mais dois trabalhos sobre o tema. Edwards Júnior (2015) realizou estudo, intitulado de "Teory Versus Reality on Colombia's Charter Schools" (Teoria Versus Realidade Nas Escolas Charter da Colômbia, em tradução livre), que analisa a lógica do modelo, especificamente os mecanismos de prestação de contas e de competição. Esse estudo descobriu que, no caso da Colômbia, os mecanismos de cada escola charter são cuidadosamente planejados e que o bom funcionamento (ou não) de uma Charter School não afeta o das outras. Fatores que de fato influenciam o resultado são a falta de competição efetiva e de opções para as famílias, além de contratos mal redigidos, que afetam a habilidade do governo em manter as escolas em um nível de prestação de serviços aceitável.

Por fim, o estudo "No Excuses Charter Schools: A Meta-Analysis of the Experimental Evidence on Student Achievement" (Escolas Charter "Sem Desculpas": Uma Meta-análise das Evidências Experimentais Sobre o Sucesso dos Alunos, em tradução livre), de autoria de Cheng, Hitt, Kisida e Mills (2015) faz análise da abordagem "Sem Desculpas”, utilizado por escolas charter muito conhecidas nos EUA. Tal método consiste principalmente em códigos disciplinares estritos, tempo de estudo estendido e apoio focado em alunos de baixo desempenho, e é muito utilizado em escolas que comportam alunos pobres e de minorias, com a obtenção de bons resultados e parâmetros acadêmicos altos. Esse é o primeiro estudo de metaanálise desse tipo de método, considerado por muitos como controverso. O estudo descobre que, de fato, existem melhorias no desempenho escolar, mas que é necessário um debate acerca dos impactos que esse tipo de escola tem sobre a política pública e os estudantes. Logo, não há realmente um consenso de que as Chater Schools sejam boas ou ruins.

$\mathrm{Na}$ verdade, o que parece é que este modelo de escola tem pontos positivos, mas que podem ser rapidamente ofuscados se existirem pontos negativos na sua formulação e implementação. Mas o que pode ser percebido de forma mais evidente é que o modelo é essencialmente americano. Foi desenvolvido e aplicado em uma lógica muito diferente da 
realidade brasileira, a qual possui entraves muito maiores quanto á administração pública, em razão de utilizar um modelo que mescla o modelo de administração francesa com o americano. Não poderia estar mais longe da realidade nacional, ainda que exista a experiência colombiana, como dito anteriormente.

\section{ORGANIZAÇÕES SOCIAIS, PARCERIAS PÚBLICO-PRIVADAS, TERCEIRIZAÇÃO: FORMAS DE PRIVATIZAÇÃO?}

Quando se falam em modelos alternativos à gestão administrativa direta e indireta, as impressões que o senso comum revela é que há grande confusão entre o uso de privatizações, entidades paraestatais e terceiro setor. A privatização é o processo de venda de empresas do setor público a um particular, que irá adquiri-la como forma de promover maior agilidade em sua atividade. Desta forma, a venda gera uma receita ao Estado, e a empresa deixa o regime de direito público para integrar o regime privado.

Citamos, como forma exemplificativa desta medida, trecho do estudo de Anuatti-Neto et. Al, onde fica evidente como ocorre este tipo de negociação:

Entre 1991 e 2001, o governo brasileiro transferiu ao setor privado o controle de mais de cem empresas estatais (referidas por EEs) e participações minoritárias em várias companhias (referidas por PMEs). Estes leilões geraram US $\$ 67,9$ bilhões em receitas, mais US $\$ 18,1$ bilhões em dívidas transferidas aos compradores, constituindo um dos maiores programas de privatização do mundo.

O governo também vendeu US\$6 bilhões em ações de firmas que permaneceram como EEs, obteve US $\$ 10$ bilhões em novas concessões de serviços públicos ao setor privado, e US $\$ 1,1$ bilhão por meio da venda de participações acionárias do Banco Nacional de Desenvolvimento Econômico e Social (BNDES) em empresas privadas (2005, p. 152).

A privatização se distingue da utilização das Organizações Sociais na medida em que opera como uma forma de administração indireta, em que há repasse de recursos públicos, controle estatal do uso desses recursos, mas a gestão e execução do objeto fica a cargo da Organização Social escolhida. Não se pode confundir, de forma alguma, a privatização com o uso de Organizações Sociais, pois não há praticamente nenhuma semelhança em seus processos (inclusive na obtenção de lucro!), a não ser a tentativa de maior dinamismo e celeridade na execução de seus objetos.

Entretanto, os meios de comunicação não utilizam as denominações corretas para indicar as ações governamentais. Exemplo disso são os títulos das manchetes que envolvem o objeto de estudo do presente artigo. O jornal Diário do Pará, em sua edição virtual de 
02/08/2015, escreveu manchete com o título de "Jatene ${ }^{2}$ quer terceirizar educação no Pará"; em outra matéria da mesma edição, o título era "SINTTEP ${ }^{3}$ diz que modelo só é bom para empresas".

De pronto, já é perceptível a confusão dos termos. A terceirização, segundo Ciro Pereira da Silva (apud RAMOS, 2001, p. 50), se configura na transferência de atividades-fim a agentes especializados, com tecnologia própria e moderna, com o intuito de preservar a qualidade e reduzir custos. No que tange à administração pública, é extremamente restrita a possibilidade de utilização da terceirização, estando adstrita a atividades como limpeza e conservação, por exemplo. Tal pode ser entendido a partir das legislações pertinentes, como o artigo $3^{\circ}$ da Lei 5.645/70:

Art. $3^{\circ}$. As atividades relacionadas com transporte, conservação, custódia, operação de elevadores, limpeza e outras assemelhadas serão, de preferência, objeto de execução indireta, mediante contrato, de acordo com o art. $10, \S 7^{\circ}$ do Dec. 200/67. (BRASIL, 1970, não paginado).

Como a administração pública está vinculada ao princípio da legalidade estrita, em que não pode fazer nada que não esteja contido na lei, é perceptível a impossibilidade de uma "terceirização" da educação pública, justamente por ser atividade fim do Estado.

Finalmente, a parceria público-privada, estabelecida pela Lei $n^{\circ} 11.079 / 04$, define esta modalidade como um contrato administrativo de concessão, nas modalidades patrocinada ou administrativa. Além disso, a lei também estabelece que:

Art. $2^{\circ}$

[...]

§ 3o Não constitui parceria público-privada a concessão comum, assim entendida a concessão de serviços públicos ou de obras públicas de que trata a Lei no 8.987, de 13 de fevereiro de 1995, quando não envolver contraprestação pecuniária do parceiro público ao parceiro privado.

§ 4o É vedada a celebração de contrato de parceria público-privada:

$\mathrm{I}$ - cujo valor do contrato seja inferior a $\mathrm{R} \$ 20.000 .000,00$ (vinte milhões de reais);

II - cujo período de prestação do serviço seja inferior a 5 (cinco) anos; ou

III - que tenha como objeto único o fornecimento de mão-de-obra, o fornecimento e instalação de equipamentos ou a execução de obra pública.

Art. 3o As concessões administrativas regem-se por esta Lei, aplicandose-lhes adicionalmente o disposto nos arts. 21, 23, 25 e 27 a 39 da Lei no 8.987, de 13 de fevereiro de 1995, e no art. 31 da Lei no 9.074, de 7 de julho de 1995. (BRASIL, 2004, não paginado)

\footnotetext{
${ }^{2}$ A manchete faz alusão ao governador do Estado do Pará em exercício, Simão Jatene, filiado ao Partido da Social Democracia Brasileira - PSDB.

${ }^{3}$ Sindicato dos Trabalhadores em Educação Pública no Estado do Pará.
} 
Ou seja, necessariamente deve existir, nos casos das parcerias público-privadas, a contraprestação entre o ente público e a entidade privada, não se inserindo aqui, portanto, contratos como o de transporte público, pois são custeados com o pagamento de passagens pelos indivíduos usuários.

Existem estudos que procuram compreender melhor como se dá a utilização das parcerias público-privadas em educação, apesar das experiências serem pontuais. Em pesquisa realizada por Lumertz (2008), busca-se investigar a concretização da parceria entre o Instituto Ayrton Sena e a educação pública no município de Sapiranga, Rio Grande do Sul. Segundo a autora deste estudo, o Instituto preta um serviço ao município através de salas de aceleração de aprendizagem, de alfabetização e de gestão da escola e sistema de ensino, com a parceria e programas em uma lógica de quase mercado, enquanto as escolas permanecem públicas (LUMERTZ, 2008, p. 51). Ao final do estudo, aponta a existência de uma tensão entre o ente privado e o ente público, no que tange à execução das tarefas que eram objeto da parceria, existindo algo como uma "briga de competências".

De qualquer forma, o Estado do Pará manifestou sua intenção de utilizar vias alternativas para dinamizar e melhorar o ensino na rede estadual. Vejamos, portanto, como foi realizado esse processo.

\section{ESTADO DO PARÁ: A TENTATIVA DE UTILIZAÇÃO DAS ESCOLAS CHARTER}

As primeiras manifestações da intenção do governo estadual de realizar este processo começaram a ser evidenciadas por sites dos principais veículos de comunicação.

A já citada matéria do jornal Diário do Pará ("Jatene quer terceirização educação do Pará”) afirma que o então secretário de Educação, Helenilson Pontes, alegou que não haveria transferência ou fechamento de escolas, nem redução de vagas ou salários.

Segundo a matéria, o Governo desejaria implantar o modelo de escolas charter, com administração pela iniciativa privada, que atende alunos de baixa renda sem custo a estes, através de financiamento público. Além disso, o projeto contaria com o apoio do Banco Mundial, que atua no Brasil com projetos de parcerias público-privadas; seriam construídas, e não entregues, 50 escolas de ensino médio no Pará, totalmente geridas pela iniciativa privada. Ao final, a reportagem afirma que um provável problema da utilização deste modelo seria o 
aumento excessivo de demanda para matrícula, o que causaria a utilização de um sistema de sorteio para a escolha dos estudantes ${ }^{4}$.

Já na outra reportagem anteriormente apontada ("SINTEPP diz que modelo só é bom para empresas"), a principal crítica é que não deveria ser adotada esta medida, e sim realizar investimento direto nas "800 escolas sucateadas que existem no Estado e na formação dos professores" (Diário do Pará On-Line, 2015). A reportagem também aborda as salas ociosas em várias escolas de Belém, as quais poderiam ser reativadas e utilizadas.

A reportagem entrevistou o coordenador geral do SINTEPP, que afirmou enfaticamente que

o modelo de terceirização vai existir só no Pará. "E nada impede que essa terceirização saia das novas escolas construídas e passe para as já existentes na rede. Será um grande negócio para as empresas gestoras que gerará um péssimo futuro para o sistema educacional no Pará", avalia. (Diário do Pará On-Line, 2015)

Por fim, a reportagem aponta como uma possível consequência ruim da adoção deste modelo a realização de um "compadrio", onde entidades privadas são selecionadas a dedo para executarem o projeto, muito mais em função de ligações pessoais com o governo do que pela capacidade técnica.

Já o sítio virtual Rede Brasil Atual, na edição virtual de número 110 de 14/09/2015, divulgou a matéria 'Goiás, Pará e Espírito Santo querem privatizar gestão de escolas públicas”. A reportagem afirma que o modelo a ser seguido por estes estados seria uma forma de livrar os governos de suas obrigações para com a educação pública, e que o Estado de Pernambuco já teria tido uma experiência fracassada quanto a escolas charter.

Em Recife, o Ginásio Pernambucano foi a primeira escola estadual a ser gerida pela iniciativa privada, em um projeto de iniciativa das empresas Philips, Tintas Coral, Eurobank e empresa de capital misto do setor de energias, Chesf. Foram removidos os 2.200 estudantes do colégio antes da sua reforma; quando o Ginásio foi reaberto, já como parte da iniciativa das empresas, foram abertas somente 300 vagas, e selecionados 26 professoras que ganhariam três vezes mais que professores da rede estadual regular, além de que poderiam receber premiação por resultados. Segundo o sítio virtual, todo o processo foi realizado com dinheiro público e sem consultas ou debates. Diz ainda a reportagem que o governo estadual do Pará iria utilizar-

\footnotetext{
${ }^{4}$ Sobre este ponto em especial, é necessário ressaltar que a reportagem parece cometer um erro. Dos estudos apontados anteriormente sobre escolas charter nos Estados Unidos, nenhum apontou a utilização de sorteio para escolha de alunos. Entretanto, existiu a utilização de sorteio para escolha de alunos no sistema de vouchers, aplicado na Colômbia, como explicitado por Rina Nogueira da Cunha $(2008$, p. 32).
} 
se de Organizações Sociais para a gestão das escolas estaduais que sofreriam a mudança (REDE BRASIL ATUAL, 2015, não paginado).

O site Unidos Para Lutar, em 11 de agosto de 2015, publicou texto em que critica duramente as medidas que viriam a ser tomadas pelo governo do Pará, ressaltando que estas seriam uma forma de privatização, ainda que o título da publicação fosse "A privatização da educação pública no Pará via parceria público-privada”. Finalmente, o site Intersindical Central da Classe Trabalhadora afirmou que o Governo do Pará "[...] Goiás têm um projeto claro de ataque à educação pública por meio de parcerias público-privadas (PPPs) ou organizações sociais (OS)[...]”, e que o processo licitatório já havia iniciado em 2015, obedecendo regras do contrato de empréstimo com o Banco Interamericano de Desenvolvimento (BID), com gasto próximo de R 11 milhões e que o contrato também seria assinado com o Banco Mundial.

É curioso notar, entretanto, que nenhuma das reportagens e textos expostos menciona reuniões com professores, pais, alunos, gestores e funcionários da Secretaria de Educação (SEDUC). Tudo leva a indicar que esse processo, se de fato estiver acontecendo, não envolveu nenhum tipo de diálogo com a população.

Em visita ao site da SEDUC, há um link para o Pacto Pela Educação, definido pelo seu sítio na internet como:

(...) um esforço liderado pelo Governo do Estado e conta com a integração de diferentes setores e níveis de governo, da comunidade escolar, da sociedade civil organizada, da iniciativa privada e de organismos internacionais, com o objetivo de promover a melhoria da qualidade da educação no Pará e, assim, tornar o Estado uma referência nacional na transformação da qualidade do ensino público. (ESTADO DO PARÁ, não paginado).

Neste mesmo endereço eletrônico, não há nada que indique a iniciativa com relação às escolas charter. A única coisa que poderia ser apontada como um indicativo é a logomarca do Banco Interamericano de Desenvolvimento. Porém, nem no site do BID, na sessão de projetos no Brasil, consta alguma informação sobre esse programa.

\subsection{Transparência, Diálogo e Participação Popular: A Dificuldade da Ausência de Dados}

A partir das informações acima expostas, foi feita tentativa de contatar a SEDUC, a fim de saber se realmente houve algum diálogo ou participação dos setores interessados nas 
medidas a serem adotadas. Entretanto, a sede da Secretaria nem ao menos atendeu os telefonemas que visavam marcar entrevistas para dialogar acerca do tema.

Porém, a Secretaria Adjunta de Ensino (SAEN) se disponibilizou para demonstrar alguns dados acerca de parceiros privados, mas nenhum deles correspondia ao objeto desta pesquisa. Quando indagada especificamente sobre o projeto que envolvia o Banco Mundial e o BID, somente foi informado que as reuniões que existiam não possuíam publicações, nem nenhum tipo de publicidade e que não se poderia ter acesso sobre as deliberações.

No site do Portal da Transparência do Estado do Pará, inexiste qualquer informação sobre as medidas, assim como o site do Pacto Pela Educação, também do Governo do Pará. Não há nada falando sobre o orçamento do projeto ou o recebimento de verbas, ou até mesmo assinatura de contratos com o BID.

Não houve, portanto, como realizar uma investigação mais aprofundada sobre o tema. Entretanto, a ausência de informações e, especialmente a falta de publicidade das reuniões e seu conteúdo, demonstram que a Administração Pública, dentro do objeto de análise, não possibilitou a participação da sociedade civil, bem como ainda não possibilita e também não disponibilizou informações suficientes para o controle das atividades administrativas.

\section{CONSIDERAÇÕES FINAIS}

Diante do exposto no presente artigo, é possível elucidar algumas reflexões.

A primeira é de que uma boa atuação administrativa deve perpassar pelo diálogo entre sociedade civil e Estado, a fim de que haja uma plena participação política dos indivíduos nas decisões que lhes afetem. A falta de diálogo e de participação são características de um Estado autoritário, em que as decisões são tomadas “de cima para baixo". Neste sentido, uma melhor concepção de Estado Democrático se reflete nas palavras do filósofo Ronald Dworkin, o qual defende um governo de parceria, ao invés de um governo de maioria:

"A conceção da parceria oferece uma justificação muito diferente - e mais bem-sucedida - do governo representativo. Dado que são os cidadãos em geral, e não um grupo em particular deles, que veem o seu impacto político diminuído ao atribuírem grande poder aos governantes eleitos, a instituição não é um défice automático na democracia. [...] É, então, necessário olhar para os pormenores dos calendários, distritos e mecanismos eleitorais, e da divisão de poder entre os governantes, para se saber se são razoavelmente pensados para proteger a legitimidade democrática que supostamente servem. Não pode haver um algoritmo para este teste; daí os debates contínuos sobre os limites de mandatos, a representação proporcional e a conveniência dos 
referendos. Pessoas e políticos sensatos discordarão sobre quais são as estruturas que aumentam as hipóteses de a comunidade mostrar respeito e preocupação geral por todos. Mas este é o teste que a conceção de parceria oferece e não a matemática mais rude do governo da maioria. ” $(2012$, p. 402)

No governo de parceria, há a consideração e respeito às vontades e aspirações dos indivíduos, ao contrário do que ocorre em uma democracia que se pauta pelo critério da quantidade, onde vencerá a vontade da maioria, ou inclusive o dos mais fortes e poderosos.

Outrossim, outro ponto a ser destacado é a falta de informações suficientes, por parte do Governo estadual, mesmo que seja seu dever prover dados acessíveis e completos para a população. Uma consequência direta é a impossibilidade de fiscalização e avaliação destas medidas pela população em geral, e pelos principais interessados (pais, alunos, professores, gestores escolares).

Outra consequência apontada é que, como não existem dados disponíveis, a opinião pública em torno do assunto só poderá se basear nas reportagens anteriormente abordadas, as quais fazem grande confusão acerca de conceitos do Direito Administrativo; mais ainda, as reportagens possuem diferenças de informações entre si, sem contar que não há garantia de que a mídia seja imparcial, podendo utilizar-se de seu poder para moldar a opinião pública de acordo com certos interesses.

Para superar esse tipo de problema, é preciso um fortalecimento real da participação popular e o reforço do dever estatal de prestar constas e fornecer informações. Só assim os direitos humanos dos indivíduos (e dos grupos, como um todo) serão respeitados.

\section{REFERÊNCIAS}

ABRAMOVICH, Victor. Una Aproximación al Enfoque de Derechos en las Estrategias y Políticas de Desarrollo. Revista de La Cepal. Vol. 88, abril de 2006. P. 35-44.

ANUATTI-NETO, Francisco; BAROSSI-FILHO, Milton; DE CARVALHO, Antônio Gledson; MACEDO, Roberto. Os efeitos da privatização sobre o desempenho econômico e financeiro das empresas privatizadas. Revista Brasileira de Economia. Vol.59 no.2, abril/junho de 2005. P. 151-175. 
BANCO INTERAMERICANO DE DESENVOLVIMENTO. Disponível em: <http://www.iadb.org/en/inter-american-development-bank,2837.html>. Acesso em: 9 ago. 2016.

BRASIL. Constituição (1988) da República Federativa do Brasil, 5 de outubro de 1988.

Disponível

em:

<http://www.planalto.gov.br/ccivil_03/constituicao/ConstituicaoCompilado.htm>. Acesso em: 1 ago. 2016.

- Lei 5645, de 10 de dezembro de 1970. Estabelece diretrizes para a classificação de cargos do Serviço Civil da União e das autarquias federais, e dá outras providências. Disponível em: 〈http://www.planalto.gov.br/ccivil_03/leis/L5645.htm〉. Acesso em: 1 ago. 2016.

Lei 11.079/04, de 30 de dezembro de 2004. Institui normas gerais para licitação e contratação de parceria público-privada no âmbito da administração pública. Disponível em: <http://www.planalto.gov.br/ccivil_03/_ato2004-2006/2004/lei/111079.htm>. Acesso em: 1 ago. 2016.

CARRUTHERS, Celeste. New schools, new students, new teachers: Evaluating the effectiveness of Charter Schools. Economics of Education Review, nº 31, p. 280-292, 2012.

CARLSON, Deven; LAVERY, Lesley; WITTE, John F.. Charter School authorizers and student achievement. Economics of Education Review, no 31, p. 254-267, 2012.

CIDA DE OLIVEIRA, TIAGO PEREIRA. Goiás, Pará e Espírito Santo querem privatizar gestão de escolas públicas. Rede Brasil Atual. Edição 110, Set. 2015. Disponível em: $\quad<\mathrm{http}: / / \mathrm{www}$.redebrasilatual.com.br/revistas/110/para-se-livrar-do-dever-de-casa6571.html>. Acesso em: 8 ago. 2016.

CHENG, Albert; HITT, Collin; KISIDA, Brian; MILLS, Jonathan N. . "No Excuses" Charter Schools: A Meta-Analysis of the Experimental Evidence on Student Achievement. EDRE Working Paper, No. 2014-11. $1^{\circ}$ de julho de 2015. 
CUNHA, Rina Nogueira da. Aplicação de Vouchers para incentivo a educação no Brasil. 2008. Dissertação (Mestrado em Finanças e Economia Empresarial) - Escola de PósGraduação em Economia, Fundação Getúlio Vargas, Rio de Janeiro, 2008.

DA LUZ, Silvia Letícia. A privatização da educação pública no Pará via parceria público-privada.

Disponível

em: <http://unidospralutar.blogspot.com.br/2015/08/aprivatizacao-daeducacao-publica-no.html >. Acesso em: 8 ago. 2016.

DIÁRIO DO PARÁ. SINTEPP diz que modelo só é bom para empresas. Belém, ago. 2015. Disponível em: <http://m.diarioonline.com.br/noticia-339205-.html〉. Acesso em: 8 ago. 2016. Jatene quer terceirizar educação no Pará. Belém, ago. 2015. Disponível em: <http://m.diarioonline.com.br/noticia-339209-.html>. Acesso em: 8 ago. 2016.

DWORKIN, Ronald. Justiça Para Ouriços. Coimbra: Almedina, 2012.

EDWARDS JR, Brent; HARTLEY, Hillary. Charter School Accountability And Competition for Schools? Theory versus Reality in Charter Schools in Colombia. 2015. Disponível em:<http://ncspe.tc.columbia.edu/working-papers/OP225.pdf $>$. Acesso em: 6 ago. 2016.

ESTADO DO PARÁ. Pacto Pela Educação. Disponível em: <http://pactopelaeducacao.pa.gov.br/>. Acesso em: 6 ago. 2016.

GRONBERG, Timothy; JANSEN, Dennis; TAYLOR, Lori. The relative efficiency of Charter Schools: A cost frontier approach. Economics of Education Review, no 31, p. 302 $317,2012$.

INTERSINDICAL. Pará e Goiás vão terceirizar a educação para a iniciativa privada. Set. 2015. Disponível em: <http://www.intersindicalcentral.com.br/para-e-goias-vaoterceirizar-aeducacao-para-a-iniciativa-privada/>. Acesso em: 8 ago. 2016. 
LEVIN, Henry. Some economic guidelines for design of a Charter School district. Economics of Education Review, n 31, 331- 343, 2012.

LUMERTZ, Juliana Selau. A Parceria Público-Privada na Educação: Implicações para a Gestão da Escola. Porto Alegre: Universidade Federal do Rio Grande do Sul, 2008. Programa de Pós-Graduação em Educação, Faculdade de Educação, Universidade Federal do Rio Grande do Sul, Porto Alegre, 2008.

PRESTON, Courtney; GOLDRING, Ellen; BERENDS, Mark; CANNATA, Marissa. School innovation in district context: Comparing traditional public schools and Charter Schools. Economics of Education Review, n 31, p. 318- 330, 2012.

RAMOS, Dora Maria de Oliveira. Terceirização na administração pública. São Paulo: LTr, 2001.

STUIT, David; SMITH, Thomas. Teacher turnover in Charter Schools. Economics of Education Review, no 31, p. 268-279, 2012.

TOMA, Eugenia; ZIMMER, Ron. Two decades of Charter Schools: Expectations, reality, and the future. Economics of Education Review, nº 31, p 209-212, 2012.

VALLA, Victor Vincent. Sobre a participação popular: uma questão de perspectiva. Cad. Saúde Pública. Vol. 14, suppl. 2, 1998. P.7-18.

Revendo o Debate em Torno da Participação Popular: ampliando sua concepção em uma nova conjuntura. In. BARATA, R.B., BRICEÑO-LEÓN, R.E., Orgs. Doenças endêmicas: abordagens sociais, culturais e comportamentais. Rio de Janeiro: Editora FIOCRUZ, 2000. P. 251-268.

WINTERS, M. A. Measuring the systemic effect of Charter Schools on public school student achievement in an urban environment: Evidence from New York City. Economics of Education Review, nº 31, p. 293-301, 2012. 
ZIMMER, Ron; GILL, Brian; BOOKER, Kevin; LAVERTU, Stephane; WITTE, John. Examining charter student achievement effects across seven states. Economics of Education Review, no 31, p. 213-224, 2001. 